\section{TUBERCULOSIS IN PEACE AND WAR* $^{*}$}

\author{
By SIR ARTHUR MACNALTY, K.C.B.
}

$\mathrm{T}$

HE National Tuberculosis Service in Great Britain was established in 1912. This is an integral part of public health, and every measure calculated to promote the health and well-being of the community is a contribution towards it. It is a great machine of organization requiring constant overhauling, alterations and improvement. Thirty years have gone to the making of it, and these have not been unbroken years of peace.

Progress in the scheme's development was arrested by the outbreak of the War of 1914-18. War conditions associated with malnutrition or semi-starvation invite tuberculosis infection. Examples of high tuberculosis morbidity were seen in the enemyoccupied countries, and the present War is likely to show a similar incidence on an even more tragic scale. The disease is one of the camp followers of war.

The standardized death-rates per million living for pulmonary tuberculosis (England and Wales) rose from 988 in 1914 to 1,498 by 1918 . Thereafter they fell. The main causes of this increase were contact infection, overcrowding, the breaking down of bodily resistance to infection through prolonged physical or mental strain, in some cases a lowered standard of nutrition and intercurrent infection, especially in. fluenza. This is how tuberculosis spreads, and war conditions augment the rate of its progress.

My representations made in 1915 that military service would heighten the incidence of tuberculosis in the adult population, and that there would be an overwhelming demand for beds in sanatoria for ex-Service men and other workers, were justified after the War of 1914-18. The total number of ex-Service men invalided out of the Services on account of tuberculosis attributable to, or aggravated by, conditions of service, amounted, approximately, to 35,000 , and provision had to be made for them as well as for civilians.

Great Britain had peace for twenty years, and in that period much was done to extend, improve and develop anti-tuberculosis work. Important features were :

(a) The surgical treatment of tuberculosis, including artificial pneumothorax, which has enabled successful treatment to be given to many intermediate and advanced cases of pulmonary tuberculosis, the arrest of whose disease was formerly regarded as either hopeless or problematical. It has also led to a more intelligent use of sanatorium and hospital treatment in relation to the individual patient.

(b) With this wider outlook and success in treatment should be associated the work done in tuberculosis by that great pioneer, Sir Pendrill VarrierJones.

(c) The improvement in X-ray technique and the consequent important aid afforded by $\mathrm{X}$-rays in the diagnosis of pulmonary tuberculosis and in the control of collapse therapy.

(d) The close association of research work in tuberculosis with practical application.

(e) The Local Government Act of 1929, which

- Substance of the Malcolm Morris Memorial Chadwick Lecture delivered on November 24 . made it possible to treat all necessitous cases of tuberculosis under the tuberculosis schemes of local authorities.

Let us look for a moment at the position in 1938, the last year of peaceful endeavour. All forms of tuberculosis were declining in our midst. In 1911 there were in England and Wales 38,422 deaths from pulmonary tuberculosis, a figure which in 1938 had declined to 21,930 . The decline in deaths from other forms of tuberculosis was even more remarkable. In England and Wales in 1938 these deaths were 14,698; in 1938 they had fallen to 4,246 . The prevention of contact infection, the increased pasteurization of milk, earlier ascertainment and skilled treatment, all no doubt had their effect in this remarkable result. It is bitter now to record that progress has for the second time in the history of the national tuberculosis scheme been retarded by the outbreak of a world war.

The baneful influence of war in favouring tuberculosis mortality is already revealed by the vital statistics of the present War. In 1939 the deaths from tuberculosis in England and Wales were 26,250. (War conditions only prevailed in a little more than three months of that year.) In 1940 they were 28,144 and in 1941 they had risen to 28,669 . The increase would be greater if non-civilians were included. Comparing with the year from mid-1938 to mid-1939 as standard, the increase in deaths from respiratory tuberculosis amounted to about 6 per cent in the first year of war and 10 per cent in the second. Using the same standard of comparison, the increase in deaths from other forms of tuberculosis amounted to $2 \cdot 4$ per cent in the first year and $17 \cdot 6$ per cent in the second year. The bulk of this increase has been due to tuberculous meningitis; in the first half of 1940 , deaths from this cause numbered 1,047 , but in the first half of 1941 the total was 1,422 , an increase of 375 , while all other forms of non-respiratory tuberculosis showed a rise of only 41 (Stocks). For the first six months of 1942 , deaths from all forms of tuberculosis were only 14,412 as compared with more than 16,000 deaths in the first half of 1941. This improvement has coincided with a lull in enemy attack.

In Wales alone no perceptible rise in deaths from tuberculosis was seen until the year 1941, and the total death-rates (tuberculosis, all forms) are lower than the death-rate for 1938. The population of Wales has increased while that of England has decreased by reason of war evacuation measures. The comparison must therefore be made with the greatest caution.

The death-rates from tuberculosis in Scotland per 100,000 were 70 in 1939,82 in 1940 and 83 in 1941 . The latter is the highest rate since 1932 .

Through the courtesy of the director-generals of the Medical Services of the Royal Navy, Army and Royal Air Foree, I am permitted to say that, as was anticipated, there has been an increase in tuberculosis in the Fighting Services since the outbreak of war. The incidence of pulmonary tuberculosis in the Army, so far as men are concerned, has shown no upward trend, and the incidence in the R.A.F. has been falling for the last six months. The increase noted does not mean that a healthy recruit is unduly exposed to contracting pulmonary tuberculosis. Service conditions may reactivate the disease or break down a poor resistance to the tubercle bacillus. With the introduction of conseription, tuberculosis in the Fighting Services is, as it were, a mirror picture 
of civilian tuberculosis. Furthermore, a Service man is under constant medical observation, and occult tuberculosis is more readily detected than in civilian life.

At the outbreak of war, there was a temporary dislocation of the tuberculosis services in some areas. There was a shortage of residential accommodation, for some of the sanatoria had to be converted into casualty hospitals, and in the excitement of war conditions, in many instances, advanced and infective patients were sent home contrary to the instructions of the Ministry of Health. The Ministry was able later in the year to release 6,000 beds for the treatment of tuberculosis. In 1940 patients were removed inland from hospitals and sanatoria in the eastern and southern coastal areas under the threat of enemy invasion. During the intensive bombing of London and other large cities, many tuberculosis wards in general hospitals were put out of action. All this has added to the difficulties of adequate residential accommodation, although, as the Minister of Health pointed out in June 1942, the main problem is the shortage of nurses for the tuberculosis service.

Evacuation and shelter life also provided their problems. Arrangements were made to meet evacuated persons' needs for continuation of treatment, and efforts have been made by medical supervision and attention to hygiene to diminish the risk of spread of infection in the shelters. Since the War, there has been an increase in tuberculosis mortality in mental hospitals and mental deficiency institutions.

Experts have pronounced that the present scale of rationing is adequate for the tuberculous, if carefully planned, as in sanatoria and hospitals. The consumptive at home or in lodgings may not be able to secure such a diet, and many think a case for special nourishment can be made out on these grounds.

War conditions are, for many reasons, favouring tuberculosis among all callings. In this increased incidence the factory workers share, but the primary causes of it lie for the most part outside the factory.

Measures of prevention and treatment may be grouped into immediate and future measures. The deadly effects of tuberculous milk are well known, and universal heat treatment of all milk would abolish tuberculosis of bovine origin, which is responsible for about 2,000 deaths in England and Wales annually as well as much suffering, illness, crippling and economic loss. Miniature or indirect radiography is an important aid to early diagnosis, but it reinforces and does not supplant clinical examination. It must not be used as a 'rule of thumb' diagnosis. Recent work in chemotherapy encourages the hope that eventually a drug may be found which will destroy the tubercle bacillus in man (vide "Chemotherapy and Tuberculosis", Nature, October 31, p. 517).

After the War, Great Britain will be faced with a greatly increased incidence of tuberculosis, particularly in ex-Service men. It is high time to marshall all our forces, and the Ministry of Health is already taking active steps. More institutional provision and beds will be needed. The village settlement, which provides the ideal solution of the tuberculosis problem, and other methods of rehabilitation will be required. The Medical Research Council favours the setting up of a national board in order to co-ordinate the planning of a national rehabilitation scheme. This was first advocated by Sir Pendrill Varrier-Jones in 1936. The work and direction of such a board is called for especially at the present time.

\section{MATHEMATICS IN THE U.S.S.R.}

\author{
By Prof. IVAN VINOGRADOV \\ Moscow (by cable)
}

THE development of the science of mathematics in Russia is comparatively recent, beginning with the establishment of the Russian Academy of Sciences in the eighteenth century, when Bernoulli and Euler, leading mathematicians of the time, were invited to Russia. These men, however, remained foreigners, and did not create what may rightly be termed a Russian school of mathematics. Lobachev. sky was the outstanding Russian mathematician, and he first propounded theories of non-Euclidean geometry, but he did not found a school of mathematics, and his ideas were not taken up by any pupils.

The real foundation of a Russian school of mathematics dates only from the latter half of last century, beginning with the work of Chebychev. Russian mathematics began at once to develop on three separate lines: the theory of numbers; the theory of probability; and the theory of approximation, the latter owing its origin to Chebyshev himself. Following on the heels of Chebyshev came a whole generation of brilliant mathematicians, among whom were Zolotaryov, Korkin, Markov, Voronoy, Lyapunov, and Steklov, whose work was in the main on the theory of numbers, the theory of probability and analysis. It was thus a characteristic of the Russian school of mathematics that its members were engaged mainly on the solution of practical mathematical problems, and generalized theories were built up on the basis of the investigation of concrete problems.

This tradition of concreteness and at the same time great profundity of investigation dates back to the time of Lomonosov, and has marked most of the work of Russian scientific men. Their research work did not follow the lines of existing scientific knowledge, but broke new ground for itself.

Shortly before the Revolution in Russia, mathematics branched out in a new direction, basing itself on the work of French mathematicians and dealing with the more abstract theory of analysis. The founders of this school were Luzin and Yegorov, after whom came a number of their brilliant pupils.

Since the Revolution the development of mathematics has been particularly successful, and Russian mathematicians have taken their place in the front rank in diverse realms of mathematical science. The first place is occupied by the theory of numbers, which, thanks to the work of Chebyshev, Markov, Voronoy and others, had already reached a high level in Russia and to which has since been added original work by Delone, Chebotarev, Helfond Schnirelman, Vinkov, Vinogradov and others. Russian mathematicians now occupy a leading place so far as the theory of numbers is concerned. The investigations of Chebyshev, Markov and Lyapunov have played a leading part in the development of the theory of probability, and their work has been maintained by Russian science, thanks to the work of Bernstein, Kolmogorov and Hinchin.

The abstract side of Russian mathematics soon liberated itself from foreign dependence and reached a level such that the eyes of mathematicians abroad began to turn towards Moscow, thanks to work on abstract mathematics by Luzin, Suslin Uryson, P. Alexandrov and others. This side of mathematics 